Several speakers discussed the production of new insecticides and other chemicals which are compatible with biological control measures. Dr J. M. Cherrett (University College of North Wales, Bangor) described work on toxic baits, and the studies of insect behaviour to try to ensure that the baits are eaten. Dr C. N. E. Ruscoe (ICI Ltd, Jealott's Hill) spoke on the possible use of insect hormones or of synthetic chemicals with similar properties as insecticides; this work is still in the "basic" stage, and the audience was interested to find a commercial organization so deeply involved. Dr D. Price Jones, also of ICI, accepted the ideal that more selective insecticides are required, and described work aimed at their production, but at the same time drawing attention to commercial and other difficulties. As the last speaker in the session on principles, Professor M. J. Way (Imperial College, London) spoke about "integrated control". He showed how the natural mechanisms which may reduce damage may continue and may even be encouraged, while at the same time insecticides may be used in the way first advocated by the late W. E. Ripper and by A. W. A. Brown, "as a stiletto, not as a scythe".

The third day was devoted to accounts of practical applications of biological control. Dr R. K. Murton (Monks Wood Experimental Station) said that few vertebrates are "absolute pests", and that attempts to eliminate them are usually wasteful and ineffective. It is better to try to exploit behavioural responses and to prevent the birds from entering crops which they may damage. $\mathrm{Mr}$ B. Stott (Ministry of Agriculture, Fisheries and Food) showed that the grass carp, at native of Asia, may control water weeds in Britain by grazing. As it does not breed except in captivity, unwanted spread and damage is unlikely. Dr $\mathbf{J}$. Rishbeth (University of Cambridge) described a practical method, now commercially available, for introducing fungi to wood to prevent the development of disease. Nematode pests of field crops are more difficult (and more expensive) to control than insects; $\mathrm{Dr}$ F. G. W. Jones (Rothamsted Experimental Station) discussed the possibilities, not yet realized, for the biological control of these animals in the soil. Rotations, with the absence for some years of a susceptible crop, are still the most effective processes.

There have been remarkable successes in both integrated and biological control in Britain. Dr R. Hull (Broom's Barn Experimental Station) described how the sugar beet crop is protected, with minimal use of insecticides. This depends on the application of research, made possible by the presence of some 140 trained field officers-a condition which does not apply to many other crops. The damage by aphids and aphid-borne viruses has been largely controlled, though larks still destroy young seedlings, spaced scientifically and grown from monogerm seeds. There is, of course, not much public enthusiasm for the control of larks, either biologically or chemically. $\mathrm{Mr}$ I. J. Wyatt (Glasshouse Crops Research Institute) described another success story-the remarkable system now practised commercially in which cucumbers are protected from spider mite attack. This pest is resistant to many insecticides but may be controlled by a predatory mite. The unusual factor is that it is found necessary to introduce the pest, and to allow it to build up to a level where it does little damage, before the predator is liberated.

The final session dealt with the future, stressing problems of importance in Britain. Mr R. Gair (Agricultural Development and Advisory Service, Cambridge) and $\mathrm{Mr} \mathrm{A}$. H. Strickland (MAFF, Harpenden) discussed the present and the future from the grower's viewpoint. Reduction in manpower, increasing mechanization, increases in the size of individual holdings and modern marketing methods all make efficient pest control increasingly important. Biological methods which are less than 100 per cent successful have therefore little future. Dr N. W. Hussey (Glasshouse Crops Research Institute), who himself played a leading part in the work previously described on pest control in cucumbers, discussed future research, and the ways in which new insecticides will affect integrated control programmes. $\mathrm{Dr}$ W. F. Jepson (Cyanamid, London) complained that today the public is more concerned about the harm that pesticides may do than with their real benefits. He showed that, in most cases, pesticides are used with safety, and he suggested that future trends in pesticide production should make for even greater safety, if public opinion does not prevent this.

Dr K. Mellanby (Monks Wood Experimental Station) gave the conservationist's viewpoint. He admitted that some ill-informed criticism of pesticides came from those interested in conserving wildlife. Real damage to wildlife had occurred from a few persistent organochlorine insecticides, and from the careless use of other chemicals, including herbicides. Many chemicals, properly used, did not, however, harm wildlife. Conservationists had often uncritically welcomed all things which could be called "biological control". Some methods, such as the production of plants resistant to pests and pathogens, cultural methods which discouraged pests and which encouraged their natural enemies, were certainly to be welcomed. Integrated control, reducing pesticide use, was also desirable. But conservationists in Britain should not welcome the introduction of living organisms from abroad without the most stringent controls.

\title{
Nomenclature for Isolated Chloroplasts
}

THE chloroplast is a complex membraneous organelle possessing both inner and outer membrane systems. To obtain isolated chloroplasts in which all the membranes are intact requires extremely careful and rapid separation procedures (D. A. Walker, Methods in Enzymology, 23, 211; 1971). Breakage or loss of the outer membranes during isolation gives preparations which show considerable differences in their biochemical properties, and for this reason there has been confusion in the nomenclature used by workers to describe their various chloroplast preparations.

With this confusion in mind $D$. $O$. Hall, in next Wednesday's Nature New Biology (January 26), has attempted, by considering both morphological and functional characteristics, to classify isolated chloroplasts into six main "types" (A to F). Type A are the only preparations which can fix carbon dioxide at high rates $(50-250 \mu \mathrm{mol} / \mathrm{mg}$ chlorophyll/h) without addition of substrate or cofactors and seem to have a fully functional outer membrane system containing specific translocase. Chloroplasts often referred to as Class
I, which possess some of their outer membrane system and appear bright and highly reflecting under the phase contrast microscope, are called type B. Type $B$ differ from type $A$ in that they are permeable to NADP, ferricyanide and ADP and can only fix carbon dioxide at very low rates.

The remaining groups represent a classification of those chloroplasts which have lost their outer membranes and cannot normally fix carbon dioxide but can, to different degrees, support electron transport and photophosphorylation when cofactors are added. Type C correspond to what Spencer and Unt called Class II chloroplasts (A ust. J. Biol. Sci., 18, 197; 1965) and are essentially intact lamellar systems having little or no stroma. Osmotically broken preparations are grouped into cither type $D$ or $\mathrm{E}$. They differ in that type $\mathrm{E}$ have their outer membranes and stroma removed by centrifugation so that these components never occur in the reaction mixture. Finally, Hall has grouped all sub-chloroplast preparations consisting of small thylakoid membrane vesicles into the category type $\mathrm{F}$. 